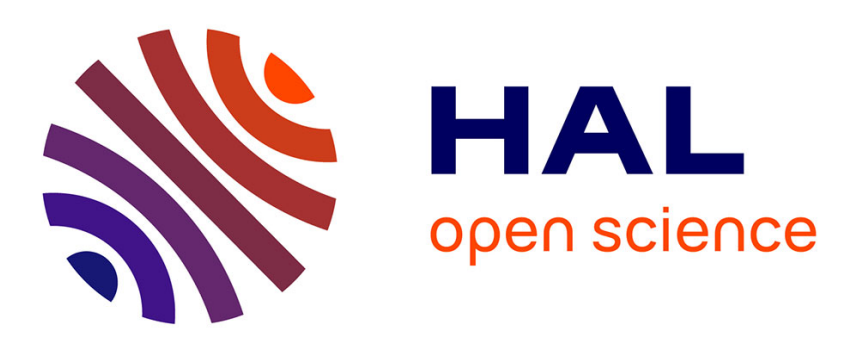

\title{
Phase transformation yield surface of anisotropic shape memory alloys
}

Karine Lavernhe Taillard, P. Blanc, Sylvain Calloch, Christian Lexcellent

\section{To cite this version:}

Karine Lavernhe Taillard, P. Blanc, Sylvain Calloch, Christian Lexcellent. Phase transformation yield surface of anisotropic shape memory alloys. Materials Science and Engineering: A, 2006, 438-440, pp.436-440. 10.1016/j.msea.2006.01.111 . hal-01021413

\section{HAL Id: hal-01021413 \\ https://hal.science/hal-01021413}

Submitted on 9 Jul 2014

HAL is a multi-disciplinary open access archive for the deposit and dissemination of scientific research documents, whether they are published or not. The documents may come from teaching and research institutions in France or abroad, or from public or private research centers.
L'archive ouverte pluridisciplinaire HAL, est destinée au dépôt et à la diffusion de documents scientifiques de niveau recherche, publiés ou non, émanant des établissements d'enseignement et de recherche français ou étrangers, des laboratoires publics ou privés. 


\title{
Phase transformation yield surface of anisotropic shape memory alloys
}

\author{
K. Taillard ${ }^{(\mathrm{a})}$, P. Blanc ${ }^{(\mathrm{b})}$, S. Calloch ${ }^{(\mathrm{c})}$, C. Lexcellent ${ }^{(\mathrm{b})}$ \\ (a) LMT Cachan \\ (b) LMARC, Besançon \\ (c) MSN-ENSIETA, Brest
}

\begin{abstract}
Two theoretical investigations i.e. a phenomenological macroscopic one and a "micro-macro" are developed for modelling the experimental surfaces of initiation of phase transformation in shape memory alloys. The eventual initial anisotropy of the materials is taken into account.
\end{abstract}

\section{INTRODUCTION}

Pseudoelasticity associated to the stress induced phase transformation between the mother phase called austenite $\mathrm{A}$ and the product phase called martensite $\mathrm{M}$ is very useful for several industrial applications.

For the design of SMA structures, the development of efficient models for the representative elementary volume (REV) is necessary. As for classical plasticity models, the definition of a yield surface of initiation of phase transformation $(\mathrm{A} \rightarrow \mathrm{M})$ under multiaxial proportional loadings at first, is a key point. In this aim, one can built phenomenological models with efficient internal variables choice [1]. An alternative way can be the use of the Crystallographical Theory of Martensite (CTM) performed by Ball, James [2,3], Bhattacharya [4] and others to know precisely the microstructure.

Therefore a homogenization process permits the prediction of the yield surfaces of phase transformation. Moreover, modelling must take into account the fact that the martensitic transformation does not proceed in a symmetrical way in the stress space [5] and particularly the asymmetry between tension and compression is obvious $[6,7]$.

At last, an another feature to consider is the initial texture of the austenitic sample which can be random, drawn or rolled.

\section{STUDIED TEXTURES [8]}

A polycrystalline material is represented by 1000 grains defined by their crystallographic orientations. Isotropic, rolled and drawn textures are defined. Each of them is characterized by the orientation of the different grains given by the three Euler's angles $\left(\varphi_{1}, \varnothing, \varphi_{2}\right)$. Isotropic texture corresponds to a random distribution of the grain orientation. In order to obtain other textures an elastoplastic model based on a selfconsistent approach [9] is used. A rolling loading up to a strain of 0.5 was simulated starting from an initial isotropic texture for a FCC $\mathrm{Cu} \mathrm{Zn} \mathrm{Al.}$

The three textures (isotropic, rolled, drawn) are now used as initial texture to describe the pseudoelastic behaviour of a $\mathrm{Cu} \mathrm{Al} \mathrm{Zn}$ or a $\mathrm{Cu} \mathrm{Al} \mathrm{Be}$ alloy and the loading transformation surface associated.

\section{PHENOMENOLOGICAL MODELLING FOR MARTENSITIC TRANSFORMATION YIELD SURFACE AT MACROSCOPIC SCALE \\ 3.1 Experimental characterization of SMA yield surfaces}

\begin{tabular}{|c|c|c|c|c|c|c|c|c|}
\hline \multirow[b]{2}{*}{ Mechanical tests } & Polycrystals & \multicolumn{3}{|c|}{ Composition at (\%) } & \multicolumn{4}{|c|}{ Transformation temperatures ${ }^{\circ} \mathrm{C}$} \\
\hline & & $\mathrm{Cu}$ & $\mathrm{Al}$ & $\mathrm{Be}$ & $M_{s}^{0}$ & $M_{F}^{0}$ & $A_{s}^{0}$ & $A_{F}^{0}$ \\
\hline $\begin{array}{l}\text { Bi-compression } \\
\text { on cubes }\end{array}$ & $\begin{array}{c}\mathrm{Cu} \mathrm{Al} \mathrm{Be} \\
\mathrm{n}^{\circ} 1\end{array}$ & \multirow{2}{*}{74.44} & \multirow{2}{*}{22.63} & \multirow{2}{*}{2.93} & 21 & -7 & 19 & 32 \\
\hline \multirow{2}{*}{$\begin{array}{l}\text { Tension-(compression) internal } \\
\text { pressure or torsion on tubes }\end{array}$} & $\begin{array}{c}\mathrm{Cu} \mathrm{Al} \mathrm{Be} \\
\mathrm{n}^{\circ} 2\end{array}$ & & & & 14 & -13 & 12 & 26 \\
\hline & $\mathrm{Cu} \mathrm{Al} \mathrm{Zn}$ & 66.84 & 23.73 & 9.4 & 14 & 5 & 17 & 20 \\
\hline \multirow{2}{*}{$\begin{array}{c}\text { Tension (compression) torsion on } \\
\text { tubes }\end{array}$} & \multirow[t]{2}{*}{$\mathrm{Ni}-\mathrm{Ti}$} & \multirow{2}{*}{\multicolumn{2}{|c|}{$\frac{\mathrm{Ni}}{50.7}$}} & $\mathrm{Ti}$ & \multirow{2}{*}{-4} & \multirow{2}{*}{-29} & \multirow{2}{*}{$-2,6$} & \multirow{2}{*}{21} \\
\hline & & & & 9.3 & & & & \\
\hline
\end{tabular}


In Figure 1 which deals with an isotropic $\mathrm{Cu} \mathrm{Al} \mathrm{Be}$ alloy, one can observe (i) the asymmetry between tension and compression, (ii) the symmetry towards the equibiaxial axis $\sigma_{1}=\sigma_{2}$, (iii) the scalar value obtained under equibiaxial tension seems higher than the one observed under tension and compression, (4i) pure shear symmetry, (5i) the strain rate $\stackrel{\text { tr }}{\text { tr }}$ seems perpendicular to the yield surface and one can refer to the same normality rule as in classical plasticity. The transverse isotropy property of $\mathrm{Cu} \mathrm{Al} \mathrm{Be}$ induces that under tension (compression)-torsion the alloy behaves as an anisotropic material (figure 2). The figure (3) reveals that it is not the case for Ni Ti under the same loading.

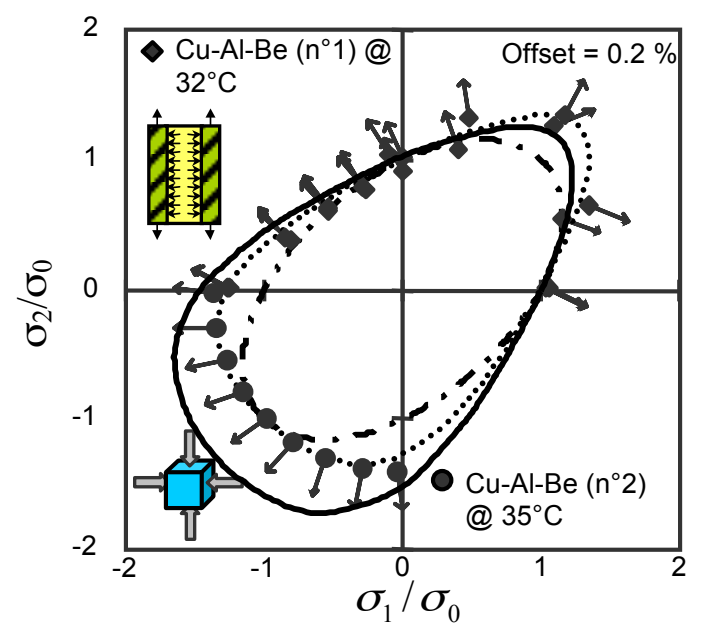

Figure 1 : - micro-macro simulation, phenomenological simulation $\bar{\sigma} \cdot g\left(y_{\sigma}\right)=$ cte, $-.-\bar{\sigma}=$ cte,$\bullet \cdot$ experiments

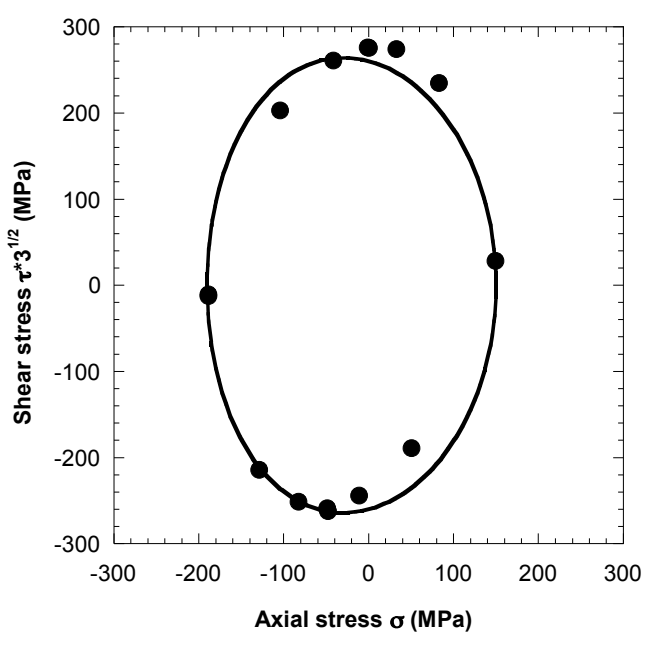

Figure 2 : Tension(compression)-torsion,,textured (drawn) Cu-Al-Be $60^{\circ} \mathrm{c}$

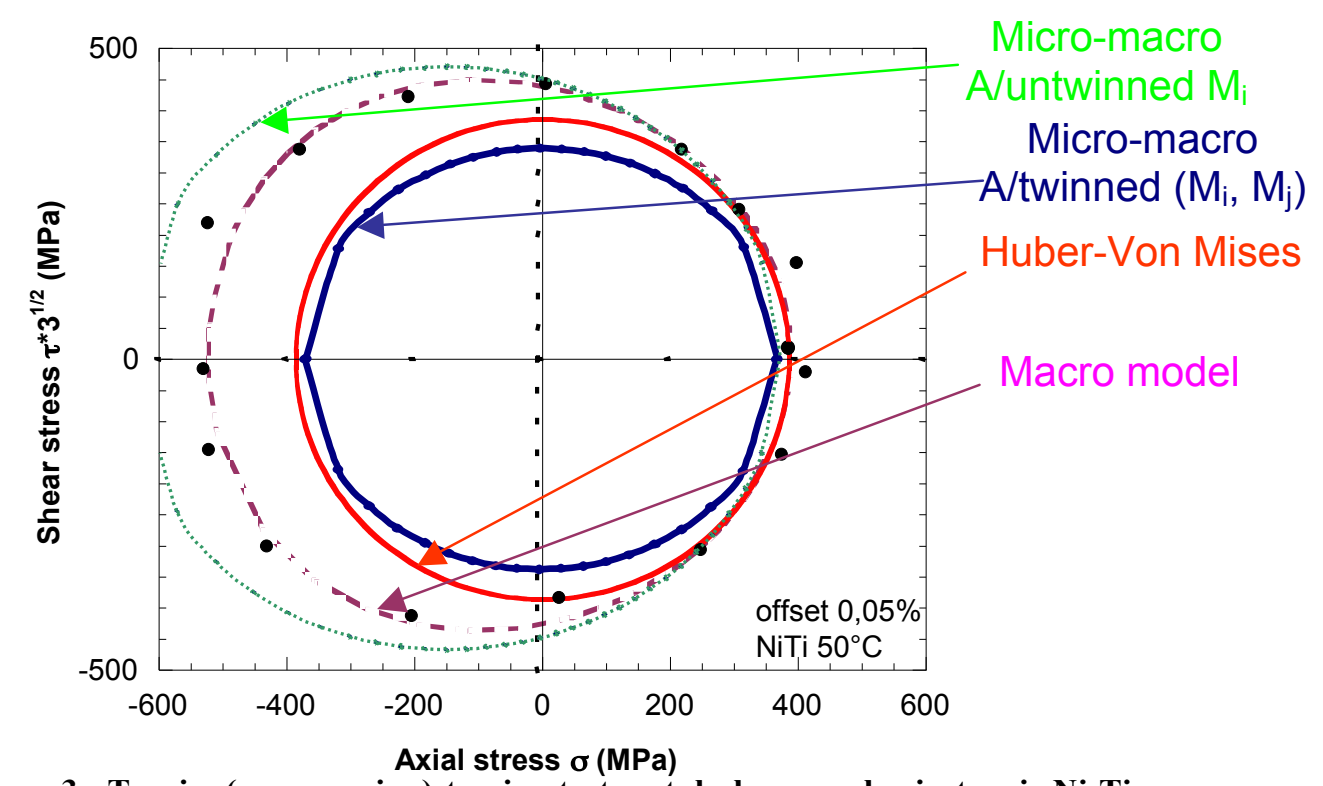

Figure 3 : Tension(compression)-torsion test on tubular sample, isotropic Ni-Ti

\subsection{Macroscopic criterion of onset transformation}

The main objective of this macroscopic criterion based on experimental results is the description of the boundary of the domain in the stress space. It means that inside the domain, the martensitic transformation is not activated. Moreover, this transformation is considered as volume invariant. For the isotropic case, Bouvet et al [10] have proposed the following equivalent stress $\sigma_{\mathrm{eq}}=\sigma_{\mathrm{eq}}\left(\bar{\sigma}, \mathrm{y}_{\sigma}\right)=\bar{\sigma} g\left(\mathrm{y}_{\sigma}\right)$ where $\bar{\sigma}=\sqrt{\frac{3}{2} \underline{\sigma}_{\mathrm{D}}: \underline{\sigma}_{\mathrm{D}}}$ 
is the Von Mises stress, $y_{\sigma}=\frac{27}{2} \frac{\operatorname{det}\left(\sigma_{\mathrm{S}}\right)}{\bar{\sigma}^{3}}, \operatorname{det}\left(\underline{\sigma}_{\mathrm{D}}\right)$ the third stress invariant of deviatoric stress tensor $\underline{\sigma}_{\mathrm{D}}$ and $g$ is a function defined by $g\left(y_{\sigma}\right)=\cos \left(\frac{1}{3} \cos ^{-1}\left(1-a\left(1-y_{\sigma}\right)\right)\right)$. The material parameter, $a$, is taken between 0 and 1 . For anisotropic case, the following extension is proposed [16]:

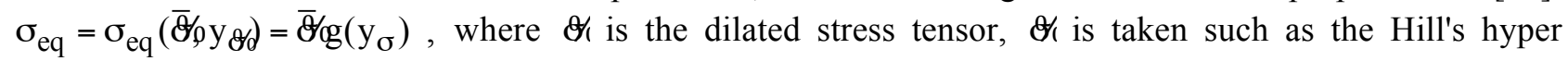
ellipsoid which is dilated by an affine transformation in an hypersphere $\underline{\xi} \sigma \underline{\underline{D}} \underline{\sigma}$. Where $\underline{\underline{D}}$ is the operator of the affine transformation (see figure 2 concerning tension (compression) torsion of drawn $\mathrm{Cu} \mathrm{Al} \mathrm{Be}$ tube).

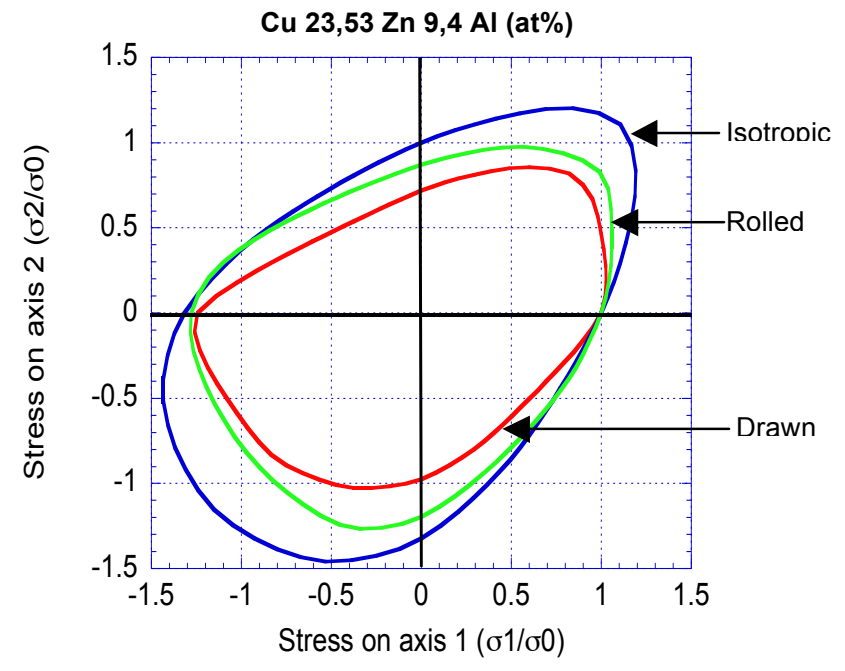

Figure 4 : Influence of texture on transformation yield surfaces

\section{CRYSTALLOGRAPHIC THEORY OF MARTENSITE UTILIZATION \\ 4.1 Theory}

The CTM used to determine the phase transformation surfaces was developed for isotropic SMA in two publications $[11,12]$. Here, we extend the investigation for textured SMA. Recalling that the CTM used to construct microstructures is a geometrically non-linear theory of martensite transformation performed by Ball and James $[2,3]$. These authors formulate a free energy function that would produce the A-M interface and relate it to crystal structure. One of the main results of this CTM is the recognition that some of the common microstructures in SMA are possible (as energy minimizing microstructures) only with exceedingly special lattice parameters.

As a summary, there are two cases

(1) certain alloys such as $\mathrm{Cu} \mathrm{Al} \mathrm{Ni,} \mathrm{Cu} \mathrm{Al} \mathrm{Zn,} \mathrm{Cu} \mathrm{Al} \mathrm{Be} \mathrm{(cubic} \rightarrow$ monoclinic type I) exhibit an undeformed interface between austenite and a single variant of martensite [13]

(2) a region consisting of fine twins of two martensite variants $i$ and $j$ can give a coherent interface with the austenite. It works for $\mathrm{Cu} \mathrm{Al} \mathrm{Ni}$ (cubic $\rightarrow$ orthorhombic), $\mathrm{Ni} \mathrm{Ti} \mathrm{(cubic} \rightarrow$ monoclinic type II) [14].

Using the theorems of [2,3], if the Hadamard equation (or compatibility condition) between austenite and a single variant of martensite are fulfilled, the microstructure (1) is obtained. If it's not the case, one has to solve the Hadamard equation at first between all the martensite variants (i) and (j) and choose all compatible twins $(i, j)$. In a second step, the resolution of the compatibility equation between A and compatible twins $(i, j)$ delivers the situation (2). However, in any case, the microstructure is viewed at stress free state and the elastic strains are neglected in comparison with the transformation strains. But the CTM permits to solve the problem for "dead loads" i.e. no change of stress or displacement in time. As it was underlined by Lexcellent and Blanc [12], the microstructure change under continuous loading or unloading is in the author's knowledge, still an opened problem (except the important fact that the austenite delivers martensite variants under stress or and temperature action). From the knowledge of lattice parameters $a_{0}$ of the cubic austenite, $(a, b, c, \theta)$ of the monoclinic martensite, the calculations deliver the microstructure of each investigated alloys : an exact interface between $\mathrm{A}$ and a single variant $\mathrm{Mi}$ for copper based alloys and a twinned martensite (Mi, $\mathrm{Mj}$ ) along with A for Ni Ti alloys. In both cases, the phase transformation strain tensor $\underline{E}_{t}$ is obtained

$$
\underline{\mathrm{E}}^{\mathrm{T}}=\frac{1}{2}\left(\underline{\mathrm{U}}^{2}-\underline{1}\right) \quad \text { with } \quad \underline{\mathrm{U}}^{2}={ }^{\mathrm{T}} \underline{\mathrm{F}} \underline{\mathrm{F}}
$$

with 


$$
\begin{aligned}
& \underline{U}=\underline{U}_{i}(i=1, \ldots, 12) \text { for } A / M i \\
& \underline{U}=(1-\lambda) \underline{U}_{i}+\lambda \underline{U}_{j} \quad(i, j=1, \ldots, 12) \text { for } A /(M i, M j)
\end{aligned}
$$

F represents the gradient of transformation $\left(\mathrm{dx}_{\mathrm{O}}^{\mathrm{r}}(\mathrm{A}) \stackrel{\mathrm{F}}{\longrightarrow} \mathrm{dx}(\mathrm{r}(\mathrm{Mj})\right.$ and $\underline{\mathrm{U}}$ is designed as the Bain strain.

\subsection{Micro-macro integration process of onset transformation surface for isotropic or textured SMA}

If we consider a biaxial loading, the stress tensor will be expressed in the sample reference configuration as

$$
\underline{\sigma}=\sigma_{1} \stackrel{1}{e}_{1} \otimes \stackrel{1}{e}_{1}+\sigma_{2} \stackrel{1}{e}_{2} \otimes \stackrel{1}{e}_{2}
$$

For each grain, the first variant appears when a thermodynamical force associated to the phase transformation is equal to zero

$$
\underline{\sigma}: \underline{\varepsilon}^{\mathrm{t}}-\mathrm{K}(\mathrm{T})=0 \quad, \quad \underline{\varepsilon}^{\mathrm{t}}={ }^{\mathrm{T}} \underline{\mathrm{R}} \underline{\mathrm{E}}^{\mathrm{t}} \underline{\mathrm{R}}
$$

$\underline{\mathrm{R}}$ is the rotation matrix from the austenite cell frame to the geometrical sample one.

The procedure used to calculate yield surface of polycrystal is purely phenomenological.

(i) a polycrystal constitutes an aggregate of $\mathrm{n}$ grains ( $\mathrm{n}$ chosen equal to 1000) with a random orientation distribution meaning an isotropic behaviour and the distribution delivered by the calculation in [8] for rolled or drawn textures. The interaction between the grains are not taken into account, (ii) under a given stress condition $\sigma^{\mathrm{o}}$ for each grain $\mathrm{k}(\mathrm{k}=1 \ldots \mathrm{n})$ and among the $\mathrm{m}$ possible variants, the one presenting the highest factor $\mathrm{K}$ is selected. A set of $\mathrm{n}$ factors $\mathrm{K}_{\mathrm{k}}^{\max }$ is determined by this method, (iii) a new set of $\mathrm{K}_{\mathrm{k}}^{\max }$ is calculated under different stress loading. $\mathrm{K}_{\text {tension, } \mathrm{k}}^{\max }$ stands for the results under uniaxial tension, (iv) a ratio called $\mathrm{r}$ and the phase transformation start stress are obtained $\mathrm{r}=\frac{\Sigma_{\mathrm{k}=1 \ldots \mathrm{n}} \mathrm{K}_{\mathrm{k}}^{\max }}{\Sigma_{\mathrm{k}=1 \ldots \mathrm{n}} \mathrm{K}_{\mathrm{tension}, \mathrm{k}}^{\max }}$ and $\underline{\sigma}^{\mathrm{t}}=\frac{1}{\mathrm{r}} \underline{\sigma}_{\mathrm{o}}$, (5i) a new stress $\underline{\sigma}_{\mathrm{o}}^{\prime}$ delivers $\underline{\sigma}_{\mathrm{t}}^{\prime}$ and so on.

\section{COMPARISON BETWEEN EXPERIMENTS AND SURFACE PREDICTIONS}

For the $\mathrm{Cu} \mathrm{Al} \mathrm{Be}$ under tension (compression) internal pressure or bicompression (fig. 1), the agreement between experiments and phenomenological and micro-macro model is good except for the equibiaxial elongation prediction for tension-compression (for micro-macro model). For the same alloy, the anisotropy revealed by tension (compression) - torsion tests is fairly taken into account by the macroscopic formulation (fig. 2). Figure 4 revealed that the micro-macro model takes into account the drawn or rolled texture see $\mathrm{Cu}$ 23.53 $\mathrm{Zn} \mathrm{9.4} \mathrm{Al} \mathrm{(at} \mathrm{\% )} \mathrm{in} \mathrm{agreement} \mathrm{with} \mathrm{the} \mathrm{prediction} \mathrm{of} \mathrm{Aleong} \mathrm{et} \mathrm{al} \mathrm{[15].} \mathrm{The} \mathrm{surface} \mathrm{predictions} \mathrm{are}$ very closed for micro-macro and phenomenological models for $\mathrm{Cu} 15-\mathrm{Zn} 17 \mathrm{Al}$ (at \%) (figs. 5,6). At last, the experiments performed on isotropic $\mathrm{Ni}$ Ti demonstrate that in this case the CTM prediction e.g. an interface with twinned martensite $(\mathrm{A} / \mathrm{Mi}, \mathrm{Mj})$ does not work, but the non predicted interface $(\mathrm{A} / \mathrm{Mi})$ works [12]. Obviously, the phenomenological macroscopic theory which represents some curve fitting also works in this case (fig. 3).

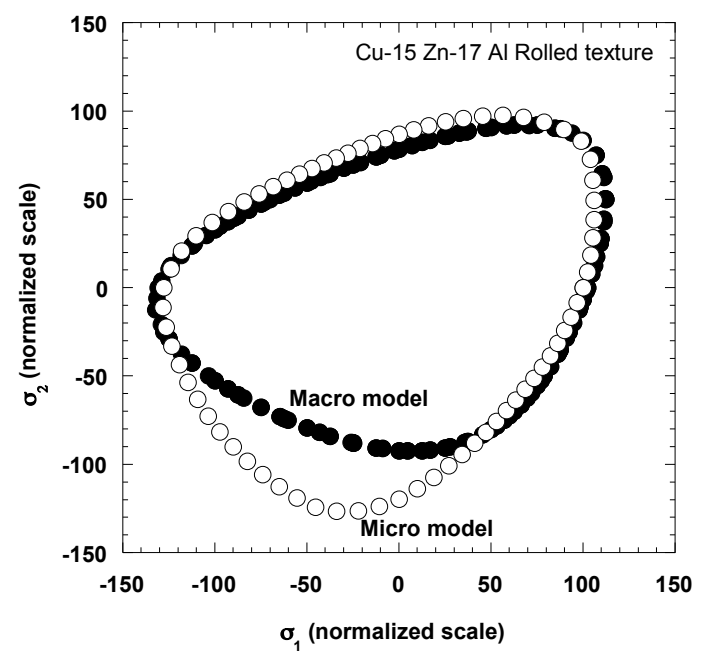

Figure 5 : Cu- 15 Zn-17 Al Rolled texture

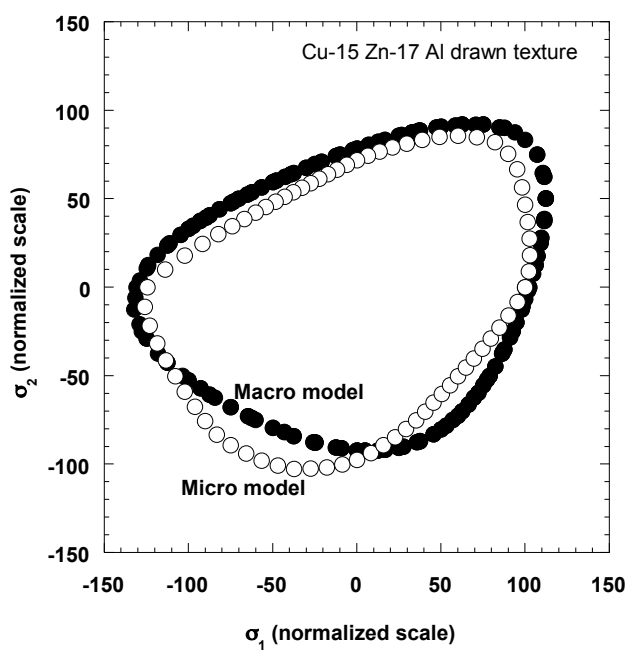

Figure 6 : Cu- 15 Zn-17 Al Drawn texture 


\section{CONCLUSION}

The modelling of yield surfaces of phase transformation is extended from isotropic to textured materials with success by an affine transformation for the phenomenological approach and by an efficient choice of grains orientation distribution. The microstructure predicted by the CTM theory can be extended to continuous loading for Copper based alloys but not for $\mathrm{Ni} \mathrm{Ti}$. The determination of microstructure evolution under continuous stress action remains an opened problem.

\section{REFERENCES}

[1] C. Bouvet, S. Calloch and C. Lexcellent, 2004. "A phenomenological model for pseudoelasticity of SMA under multiaxial proportional and non proportional loadings", Eur. J. Mech. A/Solids, 23, 37-61

[2] J.M. Ball and R.D. James, 1987. "Fine phase mixtures as minimizers of energy", Arch. Rat. Mech. Analysis, 100, 13-52

[3] J.M. Ball and R.D. James, 1992. "Proposed experimental tests of a theory of fines microstructure and the two well problem", Phil. Trans. Roy. Soc. London A 338, 389-450

[4] K. Bhattacharya, 2003. "Microstructure of martensite", Oxford series on materials modelling Oxford materials

[5] P. Sittner, Y. Hara, M. Tokuda, 1996. "Experimental study on the thermoelastic martensitic transformation in shape memory alloy polycrystal induced by combined external forces", Met. and Mat. Trans. A 26, 2923-2935

[6] P. Vacher, C. Lexcellent, 1991. Study of pseudoelastic behaviour of polycrystalline SMA by resistivity measurements and acoustic emission. Proc. Of ICM VI 6, 231-236

[7] L. Orgeas, D. Favier, 1998. "Stress-induced martensitic transformation in a Ni-Ti alloy under isothermal shear, tension and compression, Acta Mater. 46(15), 5579-5591

[8] S. Arbab Chirani, E. Patoor, 2000. "Influence of the crystallographic texture on the transformation surfaces in shape memory alloys", In Nishi Y., Bourgin P. (eds), Proceedings of the Third Japan-France Seminar on Intelligent Materials and Structures, 188-192

[9] P. Lipinski, J. Krier and M. Berveiller, 1990. "Elastoplasticité des métaux en grandes deformations : comportement global et evolution de la structure interne", Revue de Phys. Appl. 25, 361-388

[10] C. Bouvet, S. Calloch, C. Lexcellent, 2002. "Mechanical behavior of a Cu Al Be SMA under multiaxial proportional and non proportional loadings", J. of Eng. Mat. and Tech. 124, 112-124

[11] C. Lexcellent, A. Vivet, C. Bouvet, S. Calloch and P. Blanc, 2002. "Experimental and numerical determination of the initial surface of phase transformation under biaxial loading in some polycrystalline shape memory alloys", J. of Mech. and Phys. of Solids 50, 2717-2735

[12] C. Lexcellent, P. Blanc, 2004. "Phase transformation yield surface determination for some shape memory alloys", Acta Mater. 52, 2317-2324

[13] K.F. Hanes, 1999. "Bulk and thin films microstructures in untwined martensite", J. of the Mechanics and Phys. of Solids, 47(9), 1917-1939

[14] K.F. Hanes, T.W. Shield, 1999. "Microstructure in the cubic to monoclinic transitions in TitaniumNickel shape memory alloys", Acta Mater. 47(9), 2603-2617

[15] D. Aleong, C. Dumont, S. Arbab Chirani, E. Patoor, P. Mc Dowell, 2002. "Transformation surfaces of textured pseudoelastic polycrystalline $\mathrm{Cu} \mathrm{Zn} \mathrm{Al}$ shape memory alloy", J. of Int. Mat. Syst. and Struct. 13, 783-793

[16] K. Taillard, S. Calloch, C. Bouvet, C. Lexcellent, 2004. "Textured shape-memory alloys : experimental and theoretical approach to define equivalent stress and strain", ICEM 12 - 12th International Conference on Experimental Mechanics 